Author version: Int. J. Remote Sens., vol.33(9); 2012; 2925-2936

\title{
A multi-sensor climatological view of double ITCZs over the Indian Ocean
}

\author{
M.R.Ramesh Kumar ${ }^{1}$, Abhay Devasthale ${ }^{2}$, G.Levy ${ }^{3}$, Syam Sankar ${ }^{1}$, S.Bakan ${ }^{4}$ and H Grassl ${ }^{4,5}$ \\ ${ }^{1}$ National Institute of Oceanography, Dona Paula, Goa, India \\ ${ }^{2}$ Swedish Meteorological and Hydrological Institute, Norrköping, Sweden \\ ${ }^{3}$ NorthWest Research Associates, Seattle, WA, USA \\ ${ }^{4}$ Max Planck Institute for Meteorology, Hamburg, Germany. \\ ${ }^{5}$ Meteorological Institute, University of Hamburg, Hamburg, Germany
}

\begin{abstract}
We characterize climatological features of Double Inter Tropical Convergence Zones (DITCZs) over the western Indian Ocean during November- December by a synergistic analysis of the Satellite Application Facility on Climate Monitoring (CM-SAF) Hamburg Ocean Atmosphere Parameters and Fluxes from Satellite Data (HOAPS III) (1988-2005) and the NASA's A-Train data (2002-2009). We investigate rainfall, freshwater flux and cloud liquid water, cloud fraction and relative humidity over DITCZ. The daily rainfall data from the Global Precipitation Climatology Project (GPCP) are additionally used to document the DITCZs during ENSO events. An analysis of the GPCP data shows that DITCZs are clearly discernible during strong ENSO events (1997, 2002 and 2006), in sharp contrast to the DITCZs in the eastern Pacific Ocean, where they are absent during ENSOs. Further, these convergence zones on either side of the equator are of short duration, approximately 3-6 pentads during November and December. All satellite sensors data sets consistently capture major features of DITCZ. As an accurate simulation of DITCZs in coupled global climate models remains a challenge, results from the present study would provide platform for evaluating these models.
\end{abstract}

Keywords: cloud climatology, ITCZ, MODIS, AIRS, precipitation 


\section{Introduction:}

The Inter Tropical Convergence Zone (ITCZ) is a region of enhanced cloudiness and rainfall and constitutes the upward branch of the Hadley circulation, and marks the earth's meteorological equator (Waliser and Sommerville, 1994). Different authors have used different parameters to examine these convergence zones: visible images of cloudiness (Hubert et al., 1969; Saha, 1971), atmospheric circulation (Sadhuram et al., 1989), highly reflective clouds (Waliser and Gautier, 1993), rainfall (Zhang, 2001), surface wind convergence (Zheng et al., 1997), and integrated cloud liquid water content

(Ferraro et al., 1996). Earlier studies (Levy and Battisti, 1995; Tomas and Webster, 1997; Levy and Dunkerton, 2004; Toma and Webster, 2009; Levy and Patoux, 2010) suggested that the circulation of the lower troposphere is symmetrically unstable equator-ward of the ITCZ in regions where it is displaced off the equator, and such instability may interact with convection in the ITCZ. Depending on longitude, season, meteorological regime, averaging scale, and the state of ENSO, this line may be sharp or fuzzy; its distance from the equator may vary, and on occasion a second ITCZ opposite the equator may form (double ITCZ, DITCZ; Zhang, 2001). The ITCZ forms in (and often marks) the upward branch of the Hadley circulation and thus is one of the most prominent features of the tropical circulation. The DITCZ and the structure and organization of the ITCZ are very often misrepresented by global climate models (Hubert et al. 1969; Vizzy and Cook, 2006; Bellucci et al. 2010). This misrepresentation is “deleterious to an understanding of paleoclimate and predictions of future climate change” (Dunkerton, 2006). Proper representation of the ITCZ structure in climate models is important to resolving the dynamics in the tropical atmosphere, the locus of cloudiness and precipitation, and tropical storm tracks. A fairly precise knowledge of the organization of the ITCZ is also needed for the purpose of the three-dimensional extratropical circulation and tropical air-sea interactions.

Zhang (2001), while looking at the double ITCZs using monthly mean precipitation data from Climate Prediction Centre Merged Analysis of Precipitation (Xie and Arkin, 1997), found weak signals of Double ITCZs over the Indian Ocean in November. However, the temporal evolution of these in the Indian Ocean could not be ascertained, mainly because of the paucity of the data.

In the present study, the temporal evolution of double ITCZs in the Indian Ocean is characterized using the newly released Hamburg Ocean Atmosphere Parameters and Fluxes from Satellite (HOAPS) pentad 
(5-day) Version III dataset of EUMETSAT's Satellite Application Facility on Climate Monitoring (Andersson et al., 2007, Schulz et al., 2009). To investigate cloud cover and relative humidity, data from the Moderate Resolution Imaging Spectroradiometer (MODIS) and Atmospheric Infrared Sounder (AIRS) instruments onboard NASA's Aqua satellite in the NASA's A-Train constellation (L'Ecuyer and Jiang, 2010) are used. The double ITCZs over the Indian Ocean are documented in an unprecedented detail not possible in the earlier study (Zhang, 2001). This is because the life period of double ITCZs varies from 1 to 12 days with an average life span of 5-6 days (Saha, 1971), which cannot be fully resolved in analysis of monthly mean precipitation. Sadhuram et al., (1989) studied the atmospheric circulation, moisture budget and net heat exchange during the pre monsoon period $\left(18^{\text {th }}\right.$ March to $3^{\text {rd }}$ May, 1988) using data collected on board, “ Akademik Korolev”. Their study indicated the presence of DITCZ (upward motion) over the southern and northern parts of the western equatorial Indian with sinking motion in the equatorial region.

Most of the coupled general circulation models show a so-called "DITCZ Syndrome" over the Pacific Ocean (Lin, 2007; Zhang et al., 2007; Bellucci et al., 2010). This syndrome is considered mainly due to intrinsic overestimation of rainfall off the equator and cold bias in the sea surface temperatures at equator in these models. Although various studies try to understand and explain this behaviour over the Pacific Ocean (Lin, 2007; Zhang et al., 2007; Bellucci et al., 2010), there are no comparative studies evaluating representation and physical mechanism of the DITCZ over the western Indian Ocean. The climatological signatures of DITCZs presented in our study by using combined satellite data sets provide statistics needed to evaluate the ability of climate models to accurately reproduce them over the western Indian Ocean.

\section{Datasets}

The HOAPS-III data set (Andersson et al., 2007) is a satellite based climatology of precipitation, turbulent heat fluxes and freshwater budget (evaporation minus precipitation) that includes also related atmospheric state variables over the global oceans. The main advantage of this dataset is that daily, pentad and monthly means of various air-sea interaction parameters, such as sea surface temperature, specific humidity, wind speed, evaporation, rainfall, fresh water flux, integrated columnar water vapor and cloud liquid water are available in ice free regions over the global oceans from $80^{\circ} \mathrm{S}$ to $80^{\circ} \mathrm{N}$ for a 
period of more than 18 years (i.e. from $7^{\text {th }}$ July 1987 to $31^{\text {st }}$ December, 2005). All variables are derived from SSM/I passive microwave radiometers, except for the SST, which is taken from AVHRR measurements. The dataset includes multi-satellite averages, inter-sensor calibration, and an efficient sea ice detection procedure. Recent changes in this version of the dataset are a longer time series, now containing data from 1987 to 2005, a new neural network based precipitation algorithm, and the inclusion of the RSMAS/NODC Pathfinder Version 5 SST fields.

In the present study, we have used pentad-averaged data. All pentad (5-day) mean products are distributed in separate monthly files. The first day of a 5-day average period determines the monthly file wherein it is saved. Each year is subdivided in 73 pentads starting at the same day of the year. During leap years, the twelfth pentad (starting on February 25) is the average of six days. Apart from pentad and monthly means on a global $0.5^{\circ} \times 0.5^{\circ}$ grid, twice daily multi-satellite composite data on a $1^{0} \times 1^{0}$ resolution global grid are available. More information is available at http://www.hoaps.org/.

Apart from HOAPS, we use the daily Level 3 daytime products derived from the MODIS and AIRS sensors for the period from 2002 to 2009 to analyze cloud cover and relative humidity (Platnick et al., 2003; Fetzer et al., 2006; Olsen et al., 2007). The synergistic analysis of the data from all these sensors provides information on most of the crucial meteorological parameters needed to characterize the DITCZ.

\section{Method}

In the present study, the double ITCZs are defined in terms of spatial distribution of pentad rainfall data. Following Zhang (2001), we defined the ITCZ as a precipitation band that is confined in latitude and elongated in longitude that adheres to the following criteria:

a) a precipitation minimum at the equator flanked by precipitation maxima on both sides within $15^{\circ}$ latitude at each side of the equator

b) the difference between maxima and minima is more than $1.5 \mathrm{~mm} /$ day,

c) both the zonal bands extend zonally for at least $20^{\circ}$, and

d) latitudinal displacements in the precipitation maxima are less than $5^{\circ}$ 
In addition, we investigated whether precipitation exceeded the evaporation rate by a factor of 2 or more in these regions as suggested by Holton et al., (1971). In order to see the evolution of the double ITCZs in the Indian Ocean we have composited the rainfall, freshwater flux, cloud cover and cloud liquid water content for the following four stages. We tried several combinations starting from 5 days (pentad), 10 days, 15 days (fortnight) and monthly mean to look at the DITCZs over the western equatorial Indian Ocean. Only the 15 day composite brought the various phases of the DITCZs very clearly. Hence we have composited them into these four stages. Sato et al., (2007) has also used similar criteria to look into the DITCZs over the western equatorial Indian Ocean.
a) Formative phase [ $1^{\text {st }}$ to $15^{\text {th }}$ November]
b) Mature phase I [ $16^{\text {th }}$ to $30^{\text {th }}$ November $]$
c) Mature phase II [ $1^{\text {st }}$ to $15^{\text {th }}$ December $]$
d) Decaying or Dissipating phase $\left[16^{\text {th }}\right.$ to $31^{\text {st }}$ December $]$

\section{Results and discussions}

We first examine the climatological mean pentad (CMP) distribution of rainfall for the months of November and December for the study period (1988 - 2005) and subjectively determine when and where the double ITCZs exist over the Indian Ocean. During the formative phase (figure 1a), the southern ITCZ is well manifested and the northern ITCZ is diffuse. During the mature phase I (figure 1b), both the branches of the ITCZS are well established. In the mature phase II (figure 1c) the northern ITCZ is better organized than its southern counterpart. In the dissipating stage (figure 1d) the DITCZs start decaying.

Different stages of the CMP of cloud liquid water is displayed in figure 2. From the figure it can be clearly seen that the southern branch of the ITCZ is better manifested than the northern flank during the formative stage (figure 2a). During the mature phase I both the branches are well established and well separated which can be seen in figure $2 b$. The southern branch is relatively weaker than the northern part during the mature phase II (figure 2c). In the dissipating stage (figure 2d), the southern branch is again more organized compared to the northern part, which shows weaker convection. 
The CMP of freshwater flux (defined as the difference between evaporation and precipitation) clearly depicts a region of large negative values on either side of the equator during the different phases and also agrees well with the definition in that the precipitation exceeds the evaporation rates by a factor of 2 (fig. 3). The southern branch is stronger during the formative and dissipating stage as in the case of other HOAPS III parameters.

We further analyzed composites of the GPCP daily rainfall data (Huffman et al., 2009) for the years 1997, 2002, and 2006 to explore potential impacts of El Nino events on the DITCZ (fig. 4). Since GPCP data are available from 1996 onwards, only these three years show high positive values of multivariate El Nino index (MEI) in the available dataset. The DITCZ formation is quite conspicuous during these years. Due to very limited statistics, further investigations are needed to confirm robustness of the DITCZ-ENSO relationship in the equatorial Indian Ocean (and the physical reasons behind it). Nevertheless, Fig. 4 reveals an interesting feature that is in sharp contrast to the DITCZs seen in the eastern Pacific Ocean, where they are absent during the El Nino Southern Oscillation (ENSO) years, 1983, 1987, 1992 and 1997.

The composites of cloud cover from MODIS are studied for each week of November and December months for the years 2002-2009 together (fig. 5). The temporal evolution of the DITCZ is convincingly visible in the composite images of various life-cycle phases of DITCZ. The mature phase (very high cloud fraction flanked along the equator) of the DITCZ is observed mainly during the last two weeks of November and first two weeks of December. Figures 6 and 7 show zonal vertical distribution of cloud fraction and relative humidity from the daytime AIRS data at 12 pressure levels from $1000 \mathrm{hPa}$ up to $100 \mathrm{hPa}$. The retrievals between 50E-75E, the longitudinal belt where prominent DITCZ is observed, are averaged. The vertical distribution of cloud fraction (Fig. 6) further confirms a discernible flanking of upward branch of the Hadley cell during mature phases of DITCZ. The maximum in cloud fraction is observed around $200 \mathrm{hPa}$, which is mainly due to persistent cirrus decks following convective detrainment at this level. In the upper troposphere, cloud fraction in the ascending branches of DITCZ is at least double to that of the equatorial region $\left(5^{0} \mathrm{~N}-5^{0} \mathrm{~S}\right)$ during the mature phase of DITCZ. This further has an impact on the net top of the atmosphere radiative fluxes. The suppression of deep convection in the equatorial region $\left(5^{0} \mathrm{~N}-5^{0} \mathrm{~S}\right)$ can also be seen in the vertical distribution of relative 
humidity (Fig. 7). High relative humidity following moistening due to convection and convectively formed cirrus detrainment at around $200 \mathrm{hPa}$ on both sides of the equator is seen in Fig. 7. In the extratropical belts, however, convective drying in the middle troposphere is observed. Note that the moistening in the flanked regions of DITCZ in the upper troposphere is slightly enhanced compared to that in the equatorial region. As the distribution of relative humidity in the upper troposphere is more homogeneous, the signal in Fig. 7 is weaker compared to Fig. 6.

Due to the involvement of several ocean atmospheric processes and their feedbacks it is difficult to pin point whether the DITCZs are caused by oceanic processes, atmospheric dynamics, or a combination of both processes. The equatorial SST cold tongue appears to be the determining factor in the case of the DITCZs in the eastern Pacific (Lietzke, et al., 2001). We hypothesize that a similar mechanism may be at work in the western Indian Ocean, at least during ENSO events. Bjerknes et al. (1969) indicated that the spatial distribution of SST in the presence of equatorial upwelling plays an important role in displacing the ITCZs away from the equator. Levy and Battisti (1995); Levy and Dunkerton (2004), Tomas and Webster (1997), and Toma and Webster (2009), propose a different mechanism for displacing the ITCZ away from the equator - symmetric instability in the presence of cross equatorial flow and pressure gradients. The lack of a well-defined cold tongue in the Indian Ocean, and the relative uniformity in SST (Meenu et al. 2007) may explain the more diffuse appearance of the DITCZs in the Indian Ocean as compared to the Eastern Pacific, indicating that atmospheric dynamic forcing have a greater role in establishing it.

Pauluis (2004) analyzed the behavior of the Hadley circulation in the context of an idealized asymmetric atmosphere. Using a slab mixed layer representation of the Atmospheric Boundary Layer (ABL), he argued that the cross-equatorial Hadley circulation exhibits two different regimes depending on the depth of the ABL and the sea surface temperature gradient in the equatorial regions. Pauluis (2004) argued that the frictional ABL constricts mass transport across the equator, and for sufficiently strong forcing, some of the cross-equatorial transport is necessarily accomplished in the free troposphere above the ABL. In this case, rising motion is implied on the winter side of the equator; that is, a double ITCZ will result. Levy and Patoux (2010) define three dominant convective regimes associated with the symmetric stability/instability state of the lower atmosphere, the cross equatorial flow (CEF) and monsoonal forcing. In their classification, DITCZ would form in the transition period between summer 
and winter monsoon, when the lower atmosphere is symmetrically stable, as we have documented here, and in April, during the transition to the summer monsoon, as observed by Meenu et al. (2007). If we were to consolidate those recent studies with our observations, two physical mechanisms for the formation of DITCZ are possible: (i) conditions for the Pauluis (2004) mechanism may be ripe at the transition period from summer to winter monsoon, when symmetric instability of the ABL is no longer present, provided an external constraint restricts the ABL preventing it to adjust to the return flow; (ii) with the retreat of the summer monsoon from the Indian subcontinent by October and the disappearance of asymmetric forcing, weak westerlies over the Indian Ocean exist. These result in warmer SST's on both sides of the equator during the months of November and December with a cold tongue of upwelled waters at the equator, displacing the ITCZ off the equator (Bjerknes et al., 1969) symmetrically, thus forming DITCZ.

In order to look into the role of sea surface temperature on the formation of DITCZs over the study area during ENSO years, we have looked into the SST anomalies (computed as the difference between SST during ENSO composites (1992, 1997 and 2002) from the climatology), over the western equatorial Indian Ocean for the different phases of DITCZ formation. Xie and Philander (1994), suggested that the wind evaporation and SST mechanism is at work in the northward shift of ITCZ. We also feel that similar mechanism is at work over this region during ENSO events. Thus even though the SST is uniform over the study area in the climatological mean (Meenu et al., 2007), it changes significantly during the strong ENSO events, as can be seen from the SST anomaly (figure 8).

Xie and Philander (1994) attribute the ITCZ formation to the shifting of warmer SST to the northern side and cooler SST's to the southern side with a cold SST tongue at the equator. Once the warm SST is in the northern side of equator, this results in a northward surface pressure gradient, Sato et al., (2007) using the TMI SST data and Argo data have also obtained a similar result which shows the role of ocean dynamics in the formation of DITCZs over the study during the above periods. They attribute to the formation of cold SST in the western equatorial region to the upwelling of subsurface waters Thus our present study shows that both the ocean as well as atmospheric dynamics play an important role in the formation of DITCZs over the western equatorial Indian Ocean. 


\section{Conclusions}

We provide a synergistic climatological view of the evolution of double ITCZ structure in the western Indian Ocean using data from a suite of satellite sensors. Our analysis clearly shows that the lifetime of DITCZ events during the months of November and December is very short (3-6 pentads). The essential parameters (i.e. rainfall, cloud liquid water, freshwater flux, cloud cover, and relative humidity) that are needed to characterize DITCZ, all consistently capture its formative, mature and dissipation phases. In sharp contrast to the eastern Pacific where DITCZs are absent during strong ENSO years, our analysis shows that the DITCZ is well manifested over the western Indian Ocean region during strong El Nino events. The latter observation clearly requires more investigation. Similarly, we suggest physical mechanisms (Bjerknes et al., 1969: Pauluis, 2004: Levy and Patoux, 2010) that are consistent with our analysis and may explain it but further research is required in order to unequivocally relate them to the observations presented here.

\section{Acknowledgements}

The authors are grateful to the various agencies for providing the different datasets used in the present study. Freeware Ferret and GMT were used for preparing the figures. The first author (M.R.R) was supported by an ISRO Grant, and G. Levy was supported by the National Science Foundation under grant ATM-0741832. A. D. was supported by the Swedish National Space Board. They are grateful to two anonymous reviwers who have vastly improved an earlier version of the manuscript. This is NIO contribution number XXXX.

\section{References:}

ANDERSSON, A., BAKAN, S., FENNIG, K., GRASSL, H.,, CHRISTIAN-PHILLIP KLEPP, and SCHULZ, J, 2007: Hamburg Ocean Atmosphere Parameters and Fluxes from Satellite Data - HOAPS-3 - 5- days mean , doi: 10.1594/WDCC/HOAPS3_PENTAD.

BELLUCCI, A., GUALDI, S., and NAVARRA, A., 2010: The Double-ITCZ Syndrome in Coupled General Circulation Models: The Role of Large-Scale Vertical Circulation Regimes. J. Climate, 23, 1127-1145. 
BJERKNES,J., ALLISON, , L.J. KREINS, E.R., GODSHALL, F.A., l and WARNECKE, G., 1969: Satellite mapping of the Pacific tropical cloudiness, Bull. Amer.Meteorol.Soc., 50, 313-322.

DUNKERTON, T.J., 2006: A tale of two ITCZs: the Jim Holton perspective Bull. Amer. Meteorol. Soc. 87, 1492-1495.

FETZER, E. J., 2006: Preface to special section: Validation of Atmospheric Infrared Sounder Observations, J. Geophys. Res., 111, D09S01, doi:10.1029/2005JD007020.

FERRARO, R.R., WENG, F., GRODY, N.C., and BASIST, A., 1996: An Eight year (1987-1994) time series of rainfall, clouds, water vapor, snow cover and sea ice derived from SSM/I measurements. Bull. Amer.Meteor. Soc., 77, 891-905.

HOLTON, J.R., WALLACE, J.M., , and YOUNG, J.A., 1971: On boundary layer dynamics and the ITCZ. J Atmos Sci., 28, 275-280.

HUBERT, L.F., KRUGER, A.F., and WINSTON, J.S., 1969: The double inter-tropical convergence zone --- Fact or Fiction? J Atmos Sci, 26, 771-773.

HUFFMAN, G. J., ADLER, R. F., BOLVIN, D. T., and Gu, G., 2009: Improving the global precipitation record: GPCP Version 2.1, Geophys. Res. Lett., 36, L17808, doi:10.1029/2009GL040000.

L'ECUYER, T., and JIANG, J. H., 2010: Touring the atmosphere aboard the A-Train, Phys. Today, 63(7), 36-41.

LIETZKE, C.E., DESER, C., and VONDER HAAR, T.H., 2001: Evolutionary structure of the eastern Pacific double ITCZ based on satellite moisture profile retrievals J. Climate, 14, 743-751.

LEVY, G.., and BATTISTI, D. S.,1995: The symmetric stability and the low level equatorial flow, The Global Atmosphere and Ocean System, 3/4, 341-354.

LEVY, G. and DUNKERTEON, T. J., 2004: Satellite Observations of Near-Equatorial Symmetric Instability GAYANA, an International Journal of Biodiversity Oceanography, and Conservation., 68, 420.

LEVY, G., and PATOUX, J., 2010: Indian Ocean near-equatorial symmetric stability from satellite observations: An elusive connection to atmospheric convection. Int J Remote Sens., 31, 4665-4682 [ DOI: $10.1080 / 01431161.2010 .485153]$ 
LIN, J-L., 2007: The Double-ITCZ Problem in IPCC AR4 Coupled GCMs: Ocean-Atmosphere Feedback Analysis. J. Climate, 20, 4497-4525.

MEENU, S., RAJEEV, K., PARAMESWARAM, K., and SUREH RAJU, C. 2007: Characteristics of the double intertropical convergence zone over the tropical Indian Ocean. . J. Geophys. Res. 112, D11106, doi:1029/2006JD007950.

OLSEN, E. T., GRANGER, S., MANNING, E., and BLAISDELL, J., 2007: AIRS/AMSU/HSB Version 5 Level 3 Quick Start, JPL, Pasadena, USA, pp. 25.

PAULUIS, O., 2004: Boundary Layer Dynamics and Cross-Equatorial Hadley Circulation. $J$ Atmos Sci., 61, 1164-1173.

PLATNICK, S., KING, M. D., ACKERMAN, S. A., MENZEL, W. P., BAUM, B. A., RIEDI, J. C., FREY, R. A, 2003: The MODIS cloud products: Algorithms and examples from Terra, IEEE Trans. Geosci. Remote Sens., 41, 459-473.

SAHA, K., 1971: Cloud distribution over equatorial Indian Ocean as revealed by satellites, Ind. J. Meteorol. Geophys, 22 389-396.

SADHURAM, Y., KRISHNAMURTY, L., and BABU, M.T., 1989.Meteorological Results of MONSOON -88 Expedition (Pre Monsoon Period). Boundary Layer Meteorology, 48, 333-344.

SCHUlZ, J., ALBERT, P., BEHR, H.-D., CAPRION, D., DENKE, H., DEWITTE, S., DURR, B., FUCHS, P., GRATZKI, A., HECHLER, P., HOLLMANN, R., JOHNSTON, S., KARLSSON, K.-G., MANNINEN, T., MULlER, R., REUTER, M., RIIHELA, A., ROEBELING, R., SELBACH, N., TETZLAFF, A., THOMAS, W., WERSCHECK, M., WOLTERS, E., and ZELENKA, A, 2009.: Operational climate monitoring from space: the EUMETSAT Satellite Application Facility on Climate Monitoring (CM-SAF), Atmos. Chem. Phys., 9, 1687-1709, doi:10.5194/acp-9-1687-1709.

SATO, N., YONEYAMA, K., KATSUMATA, K., SHIROOKA, R., and TAKAYABU, Y.N., 2007. An ITCZ-like convergence zone over the Indian Ocean in boreal late Autumn. Geophys. Res. Lett., VOL. 34, L10811, doi:10.1029/2006GL028341.

TOMAS, R.A., and WEBSTER, P. J., 1997: The role of inertial instability in determining the location and strength of near-equatorial convection, Quart J Roy Meteor Soc., 123, 1445-1482. 
TOMA, V.E., and WEBSTER, P. J., 2009: Oscillations of the intertropical convergence zone and the genesis of easterly waves . Part I: diagnostics and theory. Clim Dyn, [DOI 10.1007/s00382-009-0584-x].

VIZY, E. K, and COOK, K. H., Development and application of a mesoscale climate model for the tropics: Influence of sea surface temperature anomalies on the West African monsoon. J. Geophys. Res. 107, 10,1029-.

WALISER, D.E., and GAUTIER, C., 1993: A satellite derived climatology of the ITCZ, J. Climate, 6, 2162-2174.

WALISER, D.E., and SOMMERVILLE, R.C.J., 1994: Preferred latitudes of the Inter Tropical Convergence Zone, J. Atmos. Sci ., 51, 1619-1639.

XIE, S.-P., and PHILANDER, S. G.H., 1994, A coupled ocean-atmosphere model of relevance to the ITCZ in the eastern Pacific, Tellus, , 46, 340- 350.

XIE, P., and ARKIN, P.A., 1997: Global Precipitation: A 17 year monthly analysis based on gauge observations, satellite estimates, and numerical model output, Bull Amer. Meteorol. Soc., 78, 25392558.

ZHANG, C., 2001: Double ITCZs.. J. Geophy. Res. 106, 11,785-11,792.

ZHANG, X., LIN, W., and ZHANG, M.,2007: Toward understanding the double Intertropical Convergence Zone pathology in coupled ocean-atmosphere general circulation models, J. Geophys. Res., 112, D12102, doi:10.1029/2006JD007878.

ZHENG, Q., YAN, X-H., LIU, W.T., TANG, W., and KURZ, D., 1997: Seasonal and interannual variability of atmospheric convergence zones in the tropical Pacific observed with ERS - 1 Scatterometer, .Geophys. Res. Lett. 24, 261-263. 


\section{Figure Captions}

Figure 1: Climatological mean pentad rainfall (mm/day) distribution over the study area showing a) Formative Phase, b) Mature Phase I, c) Mature Phase II, and d) Dissipating Phases of double ITCZ structure over the western Indian Ocean.

Figure 2:. Same as Fig. 1, but for cloud liquid water path $\left(\mathrm{Kgm}^{-2}\right)$.

Figure 3: Climatological mean pentad freshwater flux during the mature phase I

Figure 4: Composites of GPCP rainfall (mm/day) for the first two weeks of Dec. for the years 1997, 2002 and 2006 (high positive MEI values). The DITCZ structure is most conspicuous during strong El Nino events

Figure 5. Weekly composites of cloud fraction derived from MODIS for the period 2002-2009. The mature phases of DITCZ in the last two weeks of November and first two weeks of December are clearly evident

Figure 6. The daytime zonal vertical distribution of cloud fraction retrieved from the daily Level 3 AIRS data at 12 pressure levels from $1000 \mathrm{hPa}$ up to $100 \mathrm{hPa}$. The data are averaged over 50E-75E, where appearence of DITCZ is prominent as shown in Fig. 5

Figure 7. Same as in Fig. 6, but for the relative humidity.

Figure 8. Sea surface temperature anomalies over the study area $\left({ }^{0} \mathrm{C}\right)$ for the four different stages of double ITCZ over the western Indian Ocean. The anomalies are computed as the difference between the SST during ENSO composite years (1992, 1997 and 2002) minus the climatological SST. The contour intervals are in $0.2^{0} \mathrm{C}$. The values range from $-1.0^{0} \mathrm{C}$ to $1.2^{0} \mathrm{C}$. 


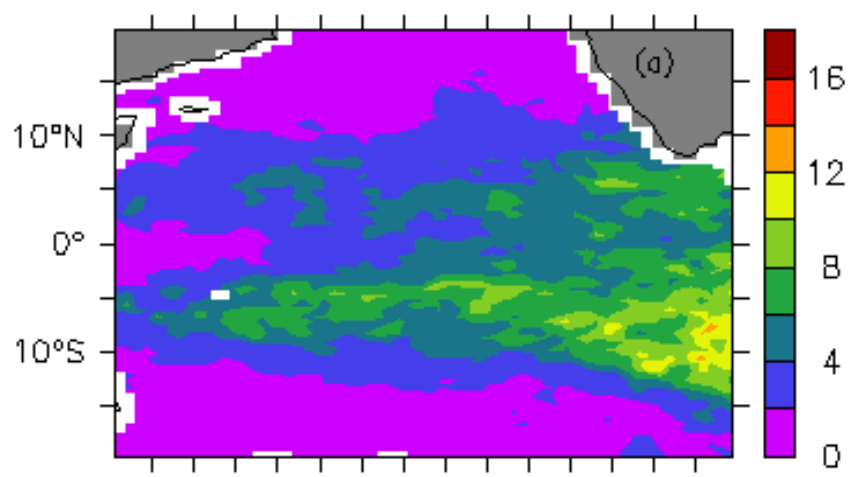

$52^{\circ} \mathrm{E} 56^{\circ} \mathrm{E} 60^{\circ} \mathrm{E} 64^{\circ} \mathrm{E} 68^{\circ} \mathrm{E} 72^{\circ} \mathrm{E} 76^{\circ} \mathrm{E}$

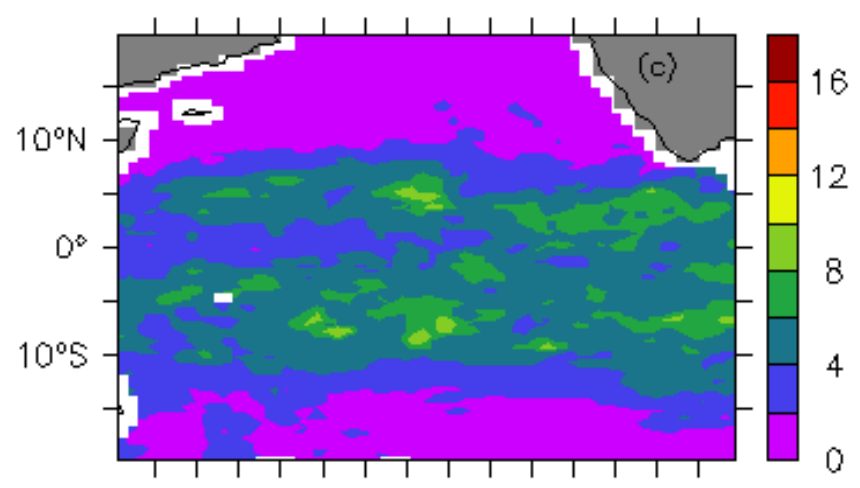

$52^{\circ} \mathrm{E} 56^{\circ} \mathrm{E} 60^{\circ} \mathrm{E} 64^{\circ} \mathrm{E} 68^{\circ} \mathrm{E} 72^{\circ} \mathrm{E} 76^{\circ} \mathrm{E}$

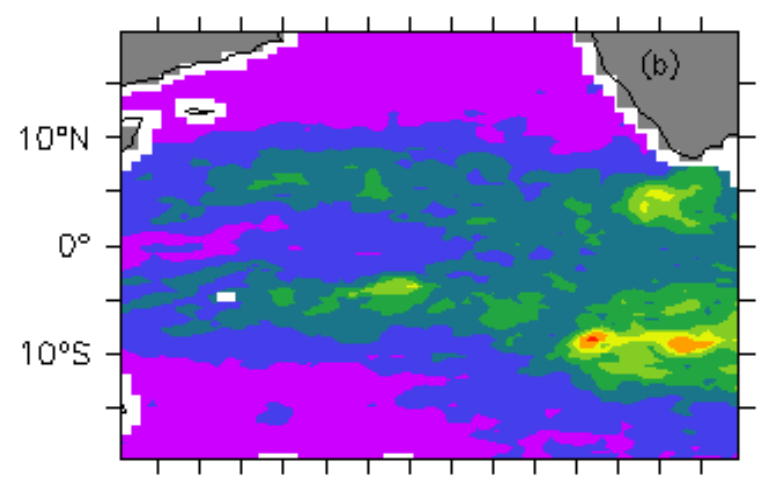

$52^{\circ} \mathrm{E} 56^{\circ} \mathrm{E} 60^{\circ} \mathrm{E} 64^{\circ} \mathrm{E} 68^{\circ} \mathrm{E} 72^{\circ} \mathrm{E} 76^{\circ} \mathrm{E}$

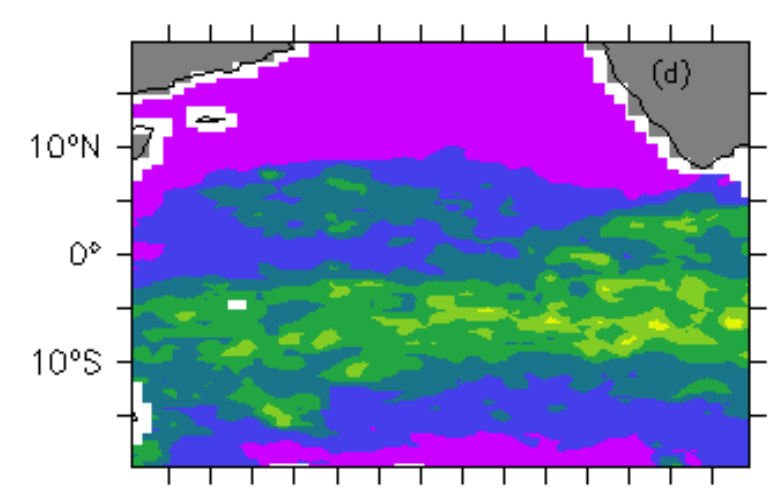

$52^{\circ} \mathrm{E} 56^{\circ} \mathrm{E} 60^{\circ} \mathrm{E} 64^{\circ} \mathrm{E} 68^{\circ} \mathrm{E} 72^{\circ} \mathrm{E} 76^{\circ} \mathrm{E}$

Figure 1 


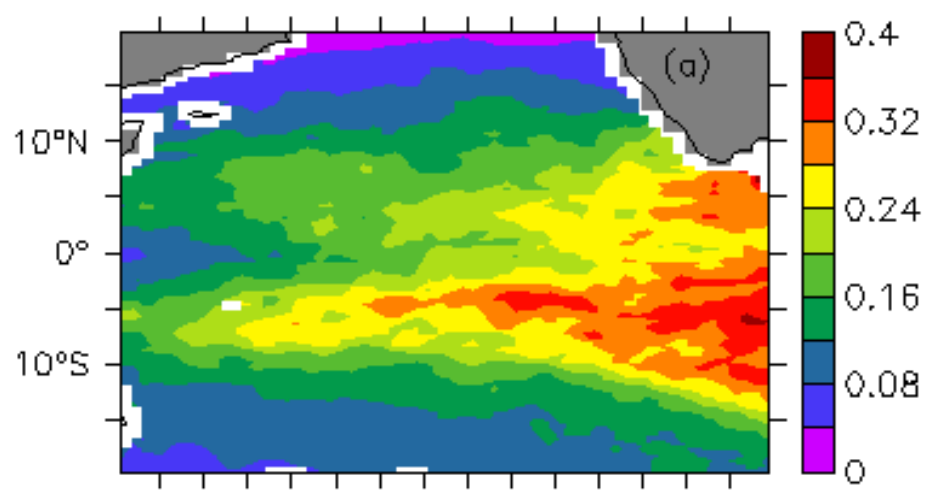

$52^{\circ} \mathrm{E} 56^{\circ} \mathrm{E} 60^{\circ} \mathrm{E} 64^{\circ} \mathrm{E} 68^{\circ} \mathrm{E} 72^{\circ} \mathrm{E} 76^{\circ} \mathrm{E}$

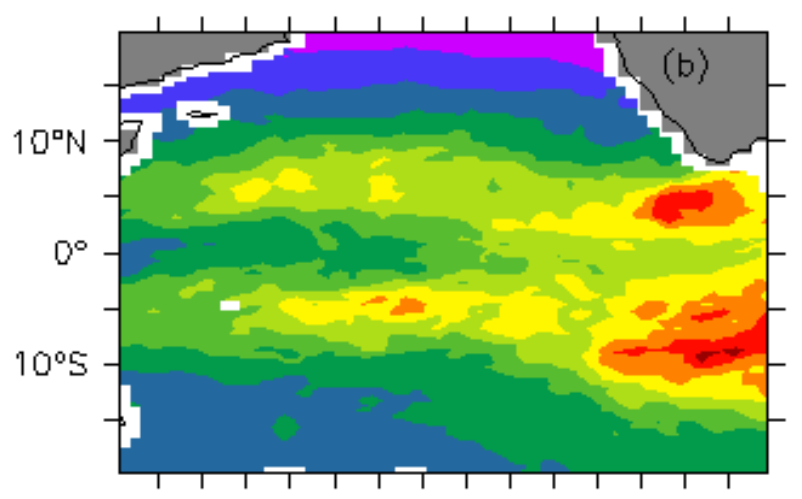

$52^{\circ} \mathrm{E} 56^{\circ} \mathrm{E} 60^{\circ} \mathrm{E} 64^{\circ} \mathrm{E} 68^{\circ} \mathrm{E} 72^{\circ} \mathrm{E} 76^{\circ} \mathrm{E}$

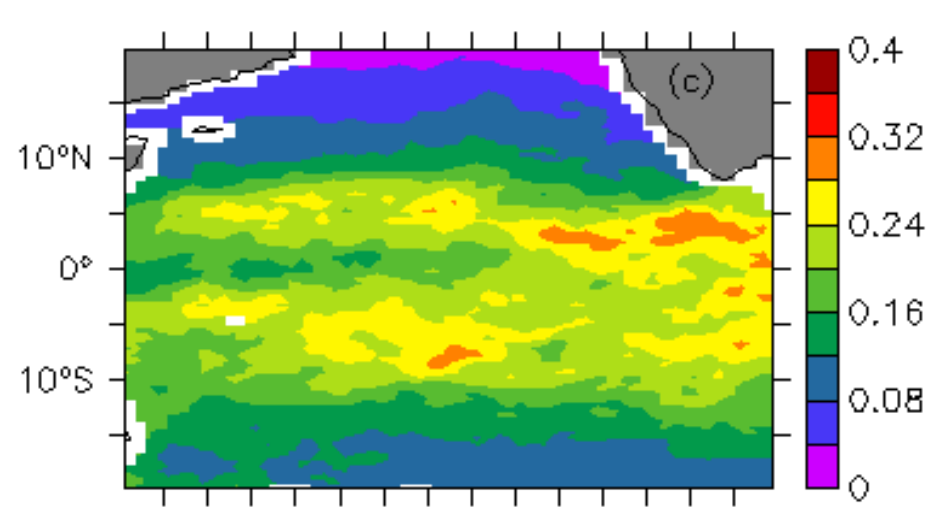

$52^{\circ} \mathrm{E} 56^{\circ} \mathrm{E} 60^{\circ} \mathrm{E} 64^{\circ} \mathrm{E} 68^{\circ} \mathrm{E} 72^{\circ} \mathrm{E} 76^{\circ} \mathrm{E}$

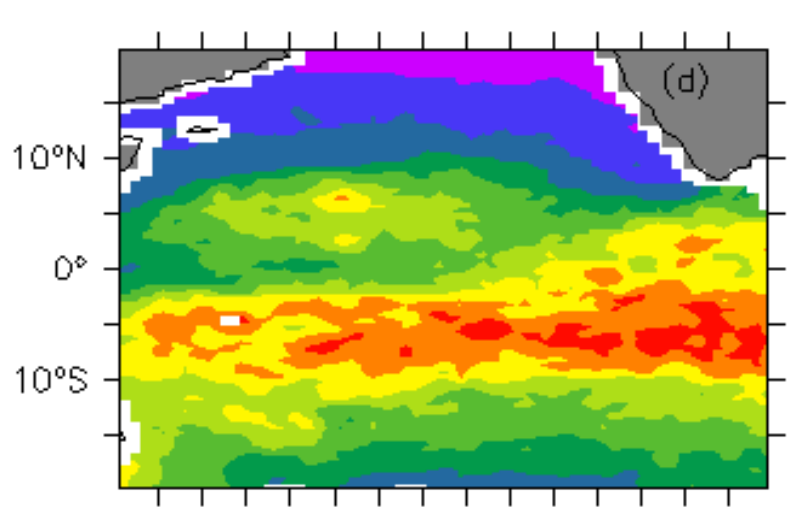

$52^{\circ} \mathrm{E} 56^{\circ} \mathrm{E} 60^{\circ} \mathrm{E} 64^{\circ} \mathrm{E} 68^{\circ} \mathrm{E} 72^{\circ} \mathrm{E} 76^{\circ} \mathrm{E}$

Figure 2 


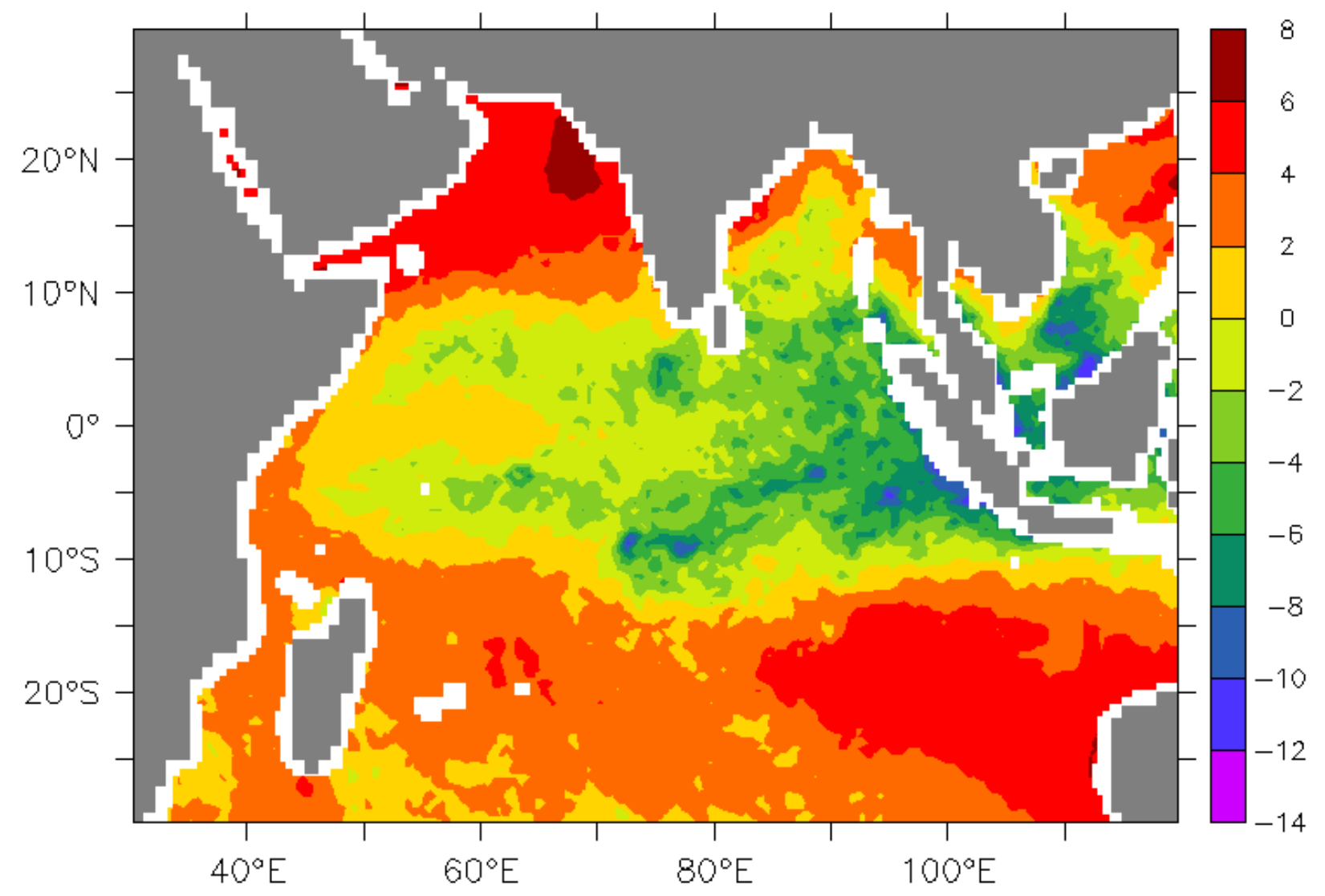

Figure 3 

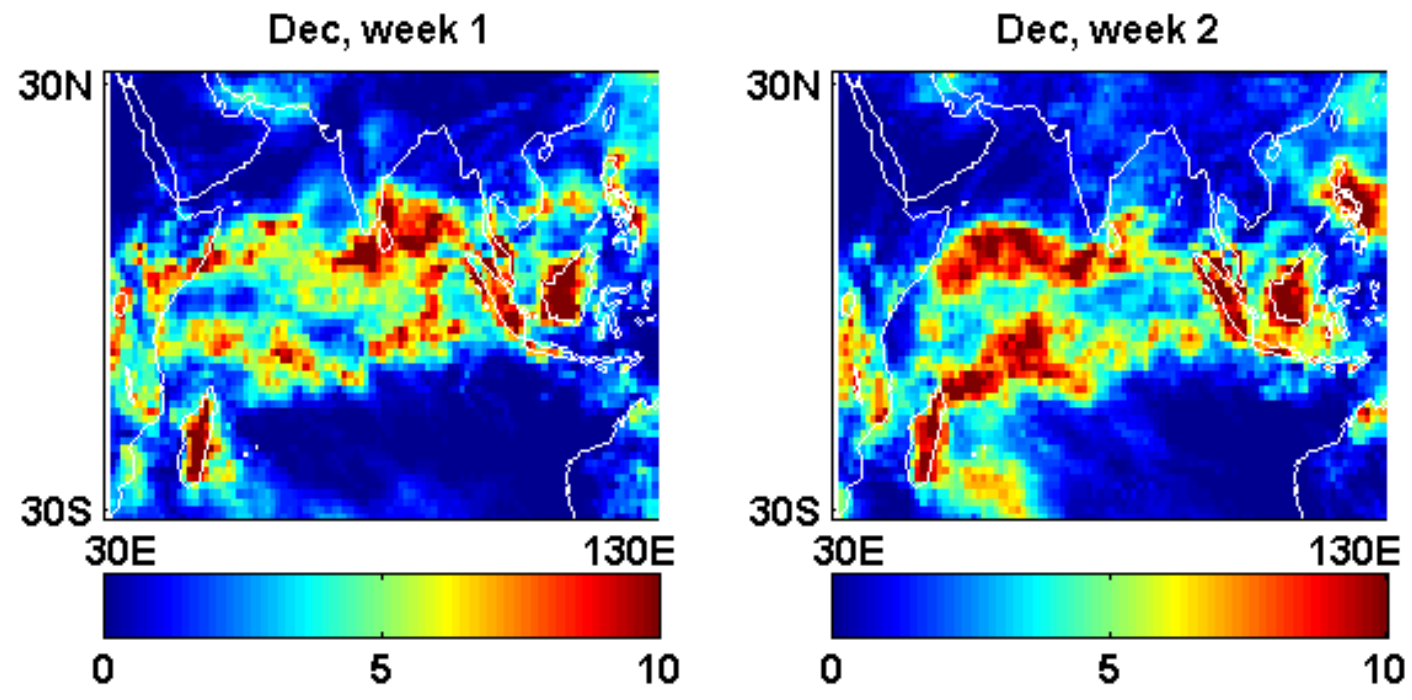

Figure 4 

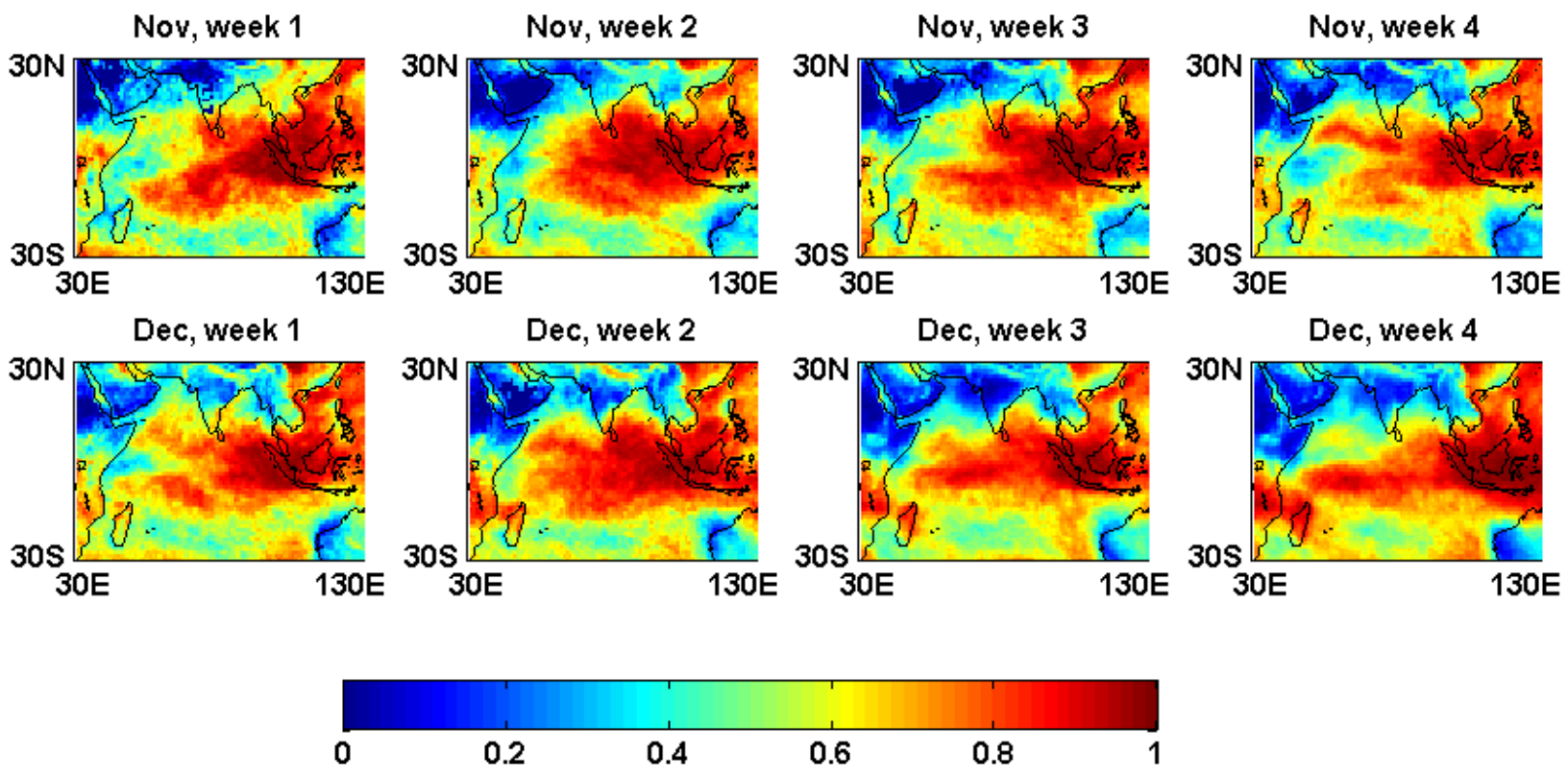

Figure 5 

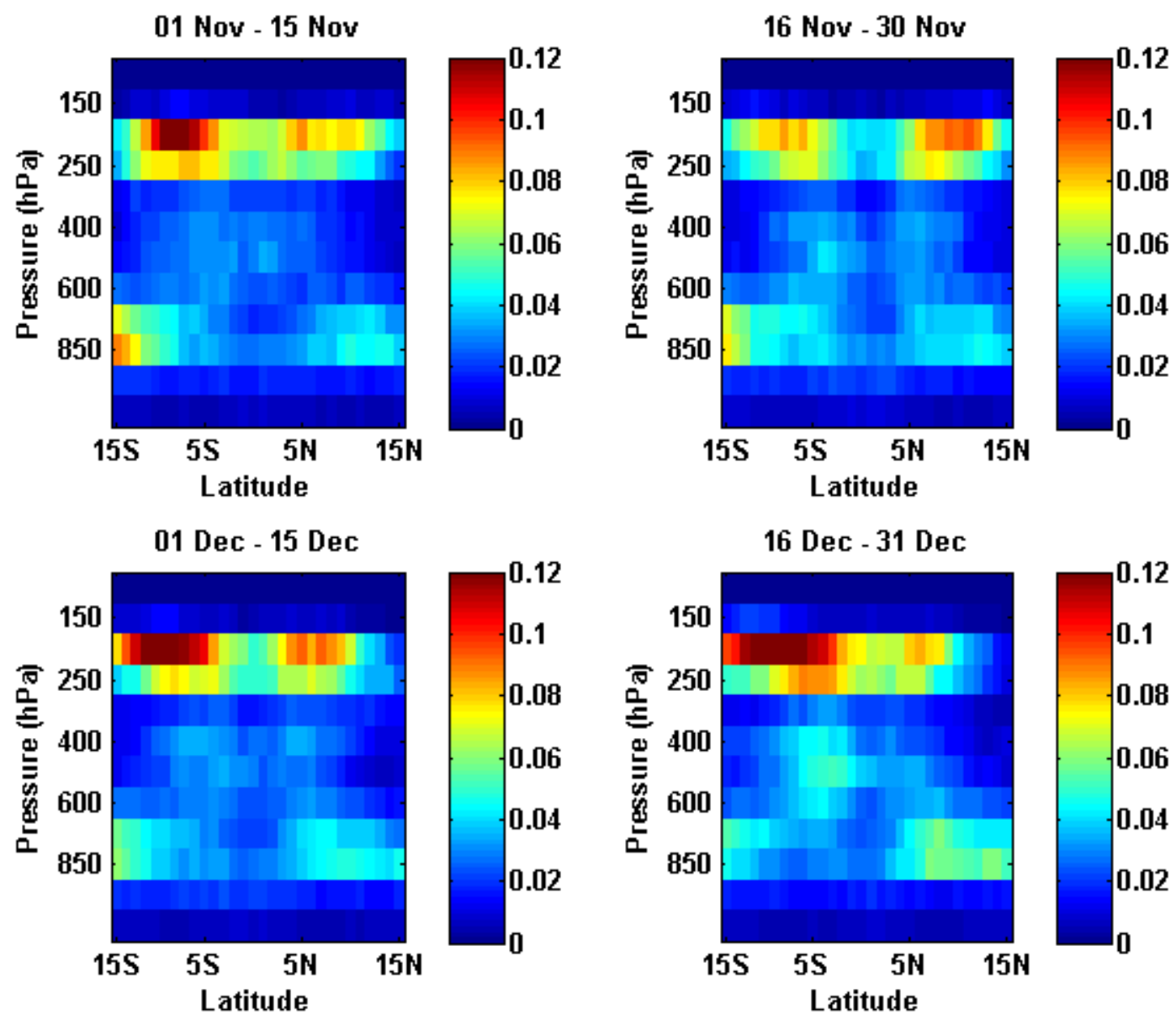

Figure 6 

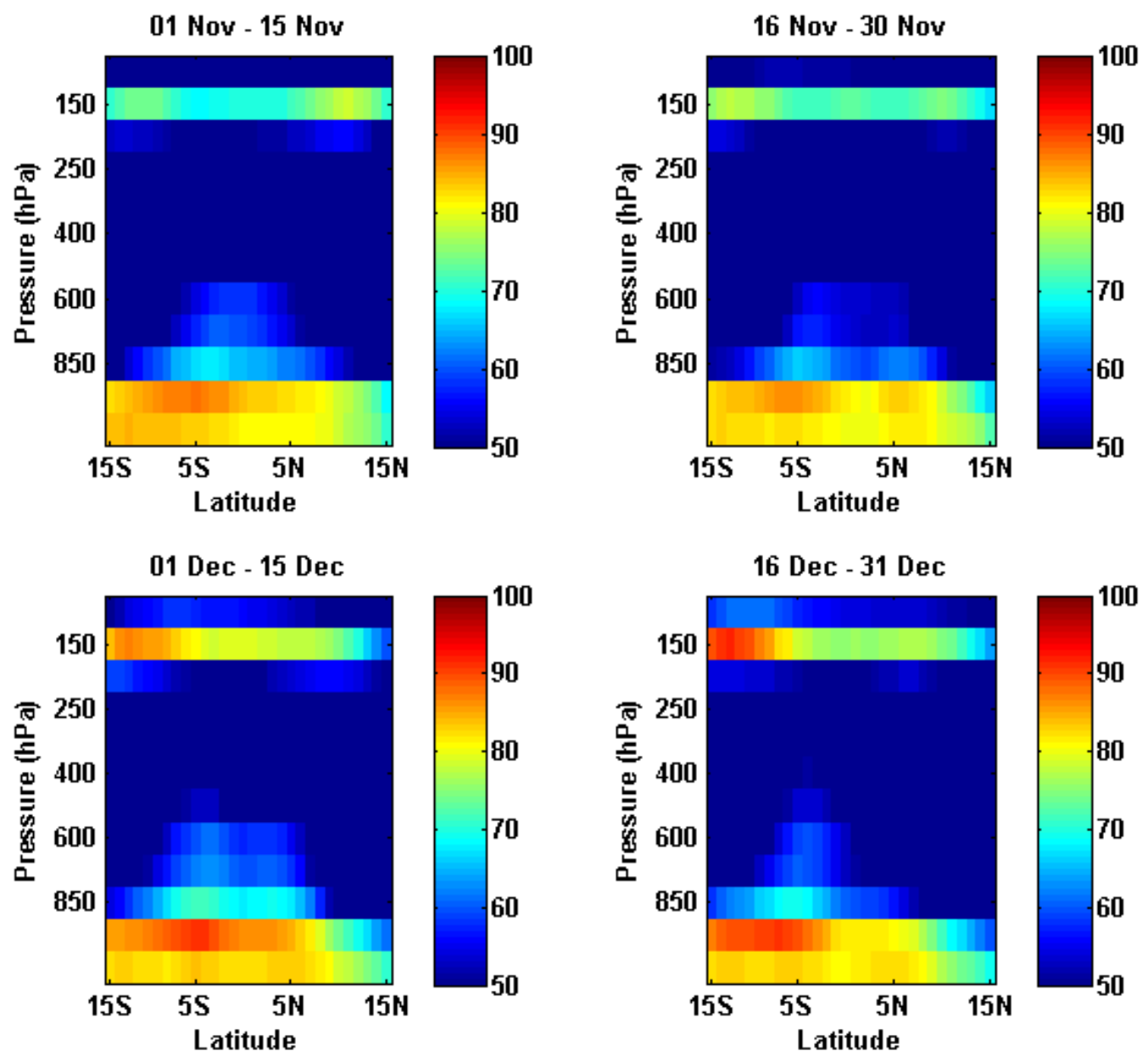

Figure 7 

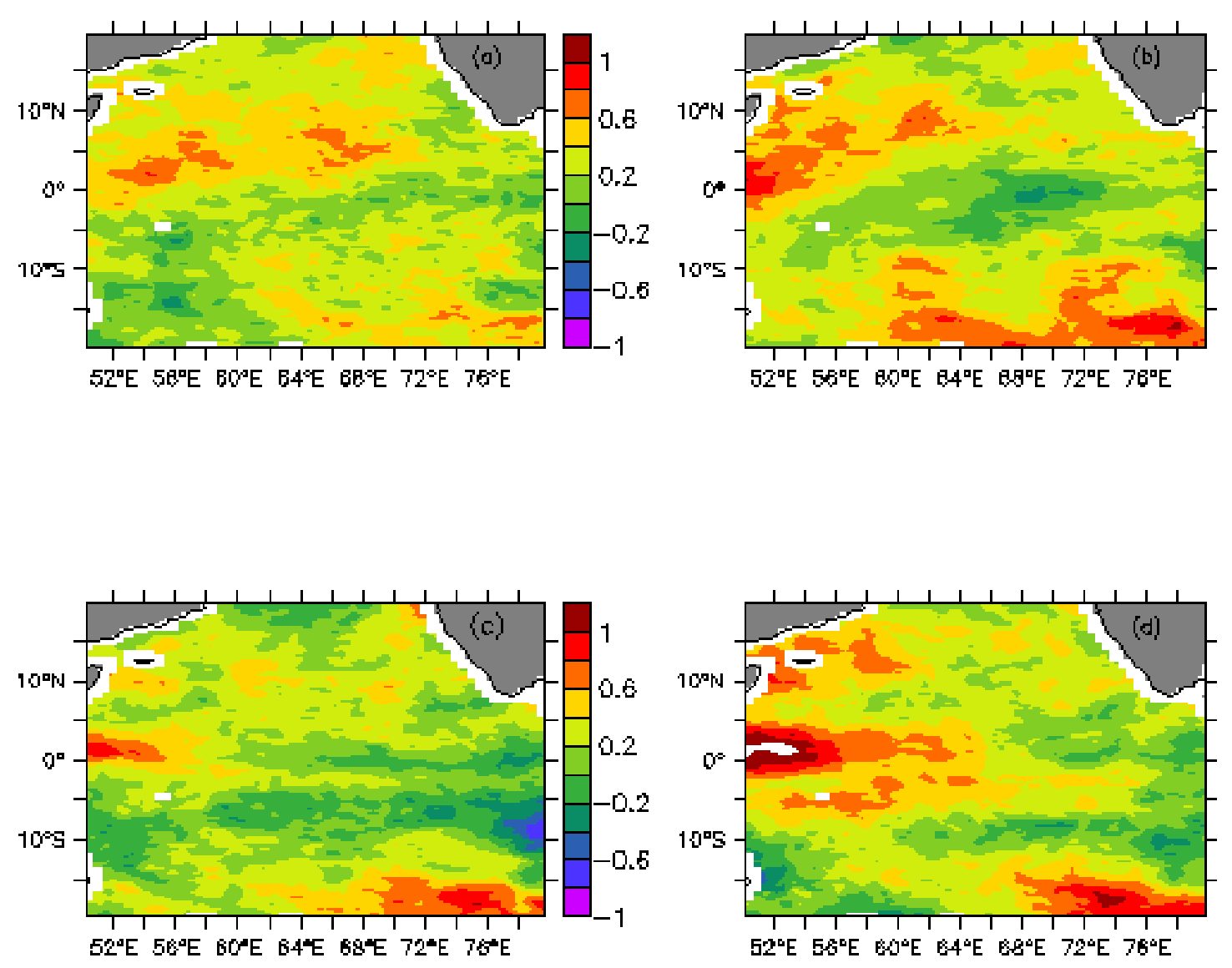

Figure 8 